\title{
Análise de padrões geofísicos e interpretação paleoambiental de poços na Bacia do Solimões
}

Almeida, J.G. L.; Araújo, J. F., Silva-Caminha, S. A.F., Universidade Federal de Mato Grosso. Faculdade de Geociências. Laboratório de Paleontologia e Palinologia da UFMT-PALMA

Copyright 2018, SBGf - Sociedade Brasileira de Geofísica

Este texto foi preparado para a apresentação no VIII Simpósio Brasileiro de Geofísica, Salinópolis, 18 a 20 de setembro de 2018. Seu conteúdo foi revisado pelo Comitê Técnico do VIII SimBGf, mas não necessariamente representa a opinião da SBGf ou de seus associados. É proibida a reprodução total ou parcial deste material para propósitos comerciais sem prévia autorização da SBGf.

\section{Resumo}

As perfilagens geofísicas dos 84 furos do Projeto Carvão no Alto Solimões realizadas pelo Serviço Geológico do Brasil (CPRM) em 1977, ainda pouco exploradas, foram aqui resgatadas para novas análises à luz de novos conhecimentos. Tais dados podem constituir uma importante fonte de informações para o entendimento do paleoambiente amazônico durante o Neógeno. Primeiramente foram destacados os poços em que foram realizadas análises bioestrátigráficas, totalizando 72poços, e destes os que apresentavam o grão Grimsdalea magnaclavata, marcador bioestratigráfico meso-neomiocênico (15-5 Ma), contido na Formação Solimões. No total 9 poços tiveram seus dados analíticos (escaneados) das formações litológicas e suas perfilagens geofísicas de raio gama, potencial espontâneo e resistência elétrica convertidas em vetores e a eles foram adicionadas as respectivas profundidades do primeiro marcador bioestratigáfico citado. Destes furos, apenas 3 foram utilizados neste trabalho, o 1AS33-AM, 1AS-105-AM e 1AS-4므 -AM. Neles os paleoambientes descritos para a Formação Solimões, variaram de ambiente com baixa energia a alta energia, corroborando com as informações descritas na literatura que, respectivamente, os definem como lacustres/pantanosos e planícies deltaicas/aluviais. O paleoambiente após o primeiro aparecimento de Grimsdalea magnaclavata indica um avanço na deposição de sedimentos finos sentido leste, a partir do mesomioceno, corroborando hipóteses aventadas por outros autores da mudança do sentido do rio amazonas neste período, tornando a geofísica destes poços uma fonte de dados confiável.

\section{Introdução}

A Amazônia Ocidental durante o neógeno foi influenciada pelo cinturão de dobramentos e cavalgamentos subandinos, que nos últimos $11 \mathrm{Ma}$ teve seu desenvolvimento tectônico máximo, resultando em grandes mudanças geológicas, climáticas e ambientais (Zalán, 2007). O pacote sedimentar depositado neste período é a Formação Solimões, principal alvo destes testemunhos.

Em relação ao paleoambiente e a paleogegrafia da amazônia no neógeno, ainda não existem modelos consensuais devido a sua ampla abrangência geográfica e localização de difícil acesso (Paz et al., 2015). Com isso, algumas sondagens realizadas na década de 80 se tornam uma fonte de dados importante para o seu entendimento.

$O$ presente trabalho baseia-se na caracterização de poços perfurados pelo Serviço Geológico do Brasil (CPRM) em 1977, na área do Projeto Carvão no Alto Solimões. O objetivo do projeto era determinar o potencial linhítico da Formação Solimões na porção ocidental do Estado do Amazonas, zona limítrofe entre Brasil, Peru e Colômbia (Maia et al., 1977).

O projeto apresenta 84 poços que atravessam o total de 14.271,96 metros de rochas cenozoicas. Devido à carência de mapeamentos em superfície os testemunhos preservados acabaram por servir de base para diversos estudos geológicos e paleontológicos realizados até os dias atuais.

Dos 84 poços perfurados apenas 72 foram estudados palinologicamente pela CPRM e destes somente 10 foram reanalisados posteriormente por Hoorn, 1993; Leite, 2006; Silva 2004; Silva 2010, Kachniasz, 2016; D'Apolito, 2016. Nestes 10 furos os autores não utilizam os dados das perfilagens geofísicos nas interpretações paleoambientais.

Todos os poços possuem informações de perfilagens geofísica de Raio Gama (RG), Potencial Espontâneo (SP) e Resistividade(RE) associadas. Destes, serão detalhados neste trabalho, o 1AS-33-AM, 1AS-105-AM e $1 \mathrm{AS}-4^{\mathrm{a}}-\mathrm{AM}$, com foco na Formação Solimões.

\section{Metodologia}

Os dados usados neste trabalho foram obtidos dos 11 volumes do Relatório Final do "Projeto Carvão no Alto Solimões", disponíveis na base PHL (Personal Home Library) da biblioteca virtual da CPRM - Serviço Geológico do Brasil, e dos trabalhos posteriores de Hoorn (1993), Silva (2004, 2010), Leite (2006), D'Apolito (2016), Kachniasz (2016), que também usaram as amostras dos furos deste projeto.

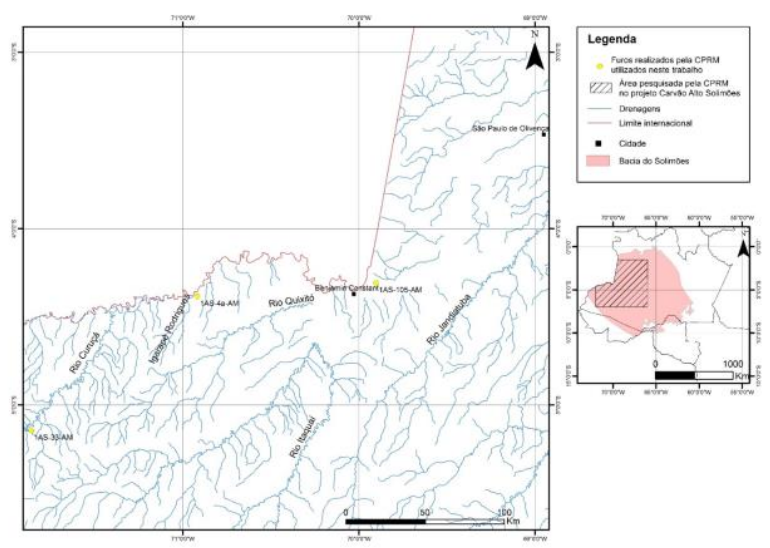

Figura 1- Mapa de localização dos poçosutilizados neste trabalho. Modificado de Maia et al. 1977. 
Para se fazer as considerações ambientais foi selecionado um datum palinológico, 0 o primeiro aparecimentodo grão de pólen Grimsdalea magnaclavata. Este grão foi escolhido por se tratar de um marcador biestratigráfico do Mioceno (Jaramillo et al., 2011) com morfologia bastante distinta. A profundidade da camada mais basal do furo em que o grão ocorre é definido como seu primeiro aparecimento - FAD (first appearance datum), este valor tabelado foi no software $E X C E L$, tais informações auxiliaram também na escolha dos poços a serem trabalhados .

Os dados geofísicos de Raio Gama (RG), Potencial Espontâneo (SP) e Resistividade(RE) extraídos da literatura foram tabelados no software EXCEL por meio do software PLOT DIGITIZER, um programa Java que permite a digitalização de pontos de dados fora de gráficos digitalizados, desenhos escalados ou fotografias ortográficas.

Após o processo de tabelamento dos dados geofísicos e litológicos foi possível exportar planilhas geradas para o software Strater 4.0 da Golden Software (licenciado), onde foram produzidas as imagens vetoriais dos furos.

Todos os 84 furos foram georreferenciados por meio do software QGIS (livre), contudo somente a geofísica da Formação Solimões dos furos 1AS-33-AM, 1AS-105-AM e 1AS-4a-AM (Figura 1) foram analisados qualitativamente (comportamento das linhas geofísicas, padrões indicativos de possíveis paleoambientes) e comparados à literatura mais atualizada.

\section{Resultados}

Furo 1AS-4a $-A M$

O furo 1 AS-4-AM atravessa um total de $353 \mathrm{~m}$ de sedimentos e rochas compartimentados na Formação Ramon, Formação Solimões e Quaternário (Figura 3. a).

A Formação Solimões neste furo é representada por um pacote de $322,50 \mathrm{~m}$ de espessura. A porção central (de 95 a $250 \mathrm{~m}$ ) da perfilagem feita nestas rochas mostra padrões geoelétricos mais irregulares com teores altos de areia ou camadas silto-areníticas, quando comparados às extremidades, que são contínuas, mais limpas e sem tendências.

As porções de extremidades desta formação (entre $15,5 \mathrm{~m}-95 \mathrm{~m}$ e entre $250 \mathrm{~m}-338 \mathrm{~m}$ ) revelam padrões que podem ser considerados de ambientes de baixa energia, enquanto que a porção central oscila entre ambientes de alta energia e baixa energia.

Furo 1AS-33-AM

O furo 1AS-33-AM atravessa um total de $405 \mathrm{~m}$ de rochas e sedimentos compartimentados na Formação Solimões e no Quaternário (Figura 3.b).

A Formação Solimões neste furo é representada por um pacote rochas sedimentares com $402,70 \mathrm{~m}$ de espessura. Suas perfilagens geofísicas indicam dois padrões bem distintos. Sendo um padrão limpo sem tendências, cilíndrico, indicando altos teores de argila no meio ou a presença de camadas de argilito. O outro padrão é representado por formas irregulares nas linhas, onde o RG muda bruscamente com a diminuição da contagem total de cintilômetros consequente, com o SP e a RE apresentando mudanças abruptas em seus valores indicando a presença de altos teores de areia ou camadas silto-areníticas.

A porção inferior possui padrões geofísicos de dois tipos de ambientes, um de alta energia (de $345 \mathrm{~m}$ até o fim do furo), de baixa energia (entre $185 \mathrm{~m}-345 \mathrm{~m}$ ). Os padrões da porção superior do furo indicam mudanças cíclicas entre estes dois possíveis ambientes.

Furo 1AS-105-AM

O furo 1AS-105-AM atravessa $338,50 \mathrm{~m}$ de rochas e sedimentos compartimentados na Formação Ramon, Formação Solimões e Quaternário (Figura 3.c).

A Formação Solimões neste furo possui $316,40 \mathrm{~m}$ de espessura. Suas linhas geofísicas desde a base se mostram irregulares, com o SP tendendo a formas de sino, indicando uma gradação de rochas com teores altos de areia ou camadas de arenito na base a rochas com teores altos de argilas no topo da mesma.

São observadas três destas gradações nas linhas de SP da Formação Solimões, a primeira mais basal de $320 \mathrm{~m}$ a $338 \mathrm{~m}$, a segunda de $280 \mathrm{~m}$ a $310 \mathrm{~m}$, e uma maior até próximo ao topo desta formação de $80 \mathrm{~m}$ a $245 \mathrm{~m}$. Estas gradações podem estar associadas sistemas retrogradantes.

Tabela 1 - FAD do grão de Grimsdalea magnaclavata de todos os autores que trabalharam nos poços do Projeto Carvão no Alto Solimões (A e B).

\begin{tabular}{|c|c|c|c|c|c|}
\hline \multicolumn{6}{|c|}{ (A) Maia et al. (1977) } \\
\hline $\begin{array}{c}\text { Furo } \\
\text { analisado }\end{array}$ & $\begin{array}{c}1^{\circ} \\
\text { aparecimento } \\
\text { de } \\
\text { Grimsdalea } \\
\text { (m) }\end{array}$ & $\begin{array}{c}\text { Furo } \\
\text { analisado }\end{array}$ & $\begin{array}{c}1^{0} \\
\text { aparecimento } \\
\text { de } \\
\text { Grimsdalea } \\
(\mathrm{m})\end{array}$ & $\begin{array}{c}\text { Furo } \\
\text { analisado }\end{array}$ & $\begin{array}{c}1^{0} \\
\text { aparecimento } \\
\text { de } \\
\text { Grimsdalea } \\
(\mathrm{m})\end{array}$ \\
\hline 1AS-1-AM & 280 & 1AS-36-AM & ausente & $\begin{array}{c}\text { AS-107- } \\
\text { AM }\end{array}$ & ausente \\
\hline 1AS-2-AM & 265,3 & $\underset{*}{1 \mathrm{AS}-37-\mathrm{AM}}$ & ausente & $\begin{array}{c}\text { 1AS-108- } \\
\text { AM }\end{array}$ & ausente \\
\hline 1AS-3-AM & ausente & 1AS-38-AM & ausente & $\begin{array}{c}\text { 1AS-109- } \\
\text { AM }\end{array}$ & ausente \\
\hline 1AS-4-AM & ausente & 1AS-39-AM & 158,7 & $\begin{array}{c}\text { 1AS-110- } \\
\text { AM }\end{array}$ & ausente \\
\hline $\begin{array}{c}\text { 1AS-4A- } \\
\mathrm{AM}^{*}\end{array}$ & ausente & $1 \mathrm{AS}-40-\mathrm{AM}$ & ausente & $\begin{array}{c}\text { 1AS-111- } \\
\text { AM }\end{array}$ & Ausente \\
\hline 1AS-5-AM & 162,8 & 1AS-41-AM & ausente & $\begin{array}{c}\text { 1AS-112- } \\
\text { AM }\end{array}$ & ausente \\
\hline 1AS-7D-AM & ausente & $1 \mathrm{AS}-42-\mathrm{AM}$ & ausente & $\begin{array}{c}\text { 1AS-113- } \\
\text { AM }\end{array}$ & ausente \\
\hline 1AS-8-AM & 237,11 & 1AS-43-AM & 46,5 & $\begin{array}{c}\text { 1AS-114- } \\
\text { AM }\end{array}$ & 25,7 \\
\hline 1AS-9-AM & $\begin{array}{c}\text { Rel.vol. 7, } \\
\text { pg.104 }\end{array}$ & 1AS-44-AM & ausente & $\begin{array}{c}\text { 1AS-115- } \\
\text { AM }\end{array}$ & ausente \\
\hline 1AS-10-AM & ausente & $1 \mathrm{AS}-45-\mathrm{AM}$ & ausente & $\begin{array}{c}\text { 1AS-116- } \\
\text { AM }\end{array}$ & 51,5 \\
\hline 1AS-14-AM & ausente & 1AS-46-AM & ausente & $\begin{array}{c}\text { 1AS-117- } \\
\text { AM }\end{array}$ & ausente \\
\hline 1AS-15-AM & ausente & 1AS-47-AM & ausente & $\begin{array}{c}\text { 1AS-118- } \\
\text { AM }\end{array}$ & ausente \\
\hline 1AS-18-AM & ausente & 1AS-48-AM & ausente & $\begin{array}{c}\text { 1AS-119- } \\
\text { AM }\end{array}$ & ausente \\
\hline 1AS-19-AM* & ausente & 1AS-49-AM & ausente & $\begin{array}{c}1 \text { AS-120- } \\
\text { AM }\end{array}$ & ausente \\
\hline 1AS-20-AM & ausente & 1AS-51-AM & 135,7 & $\begin{array}{c}\text { 1AS-122- } \\
\text { AM }\end{array}$ & ausente \\
\hline 1AS-21-AM & ausente & 1AS-52-AM & ausente & $\begin{array}{c}\text { 1AS-123- } \\
\text { AM }\end{array}$ & ausente \\
\hline 1AS-22-AM & 135,55 & 1AS-53-AM & 27,42 & $\begin{array}{c}\text { 1AS-125- } \\
\text { AM }\end{array}$ & ausente \\
\hline 1AS-23-AM & ausente & 1AS-54-AM & 31,87 & $\begin{array}{c}\text { 1AS-126- } \\
\text { AM }\end{array}$ & ausente \\
\hline 1AS-26-AM & ausente & 1AS-56-AM & ausente & $\begin{array}{c}\text { 1AS-130- } \\
\text { AM }\end{array}$ & ausente \\
\hline $1 \mathrm{AS}-27-\mathrm{AM}^{*}$ & 143,95 & 1AS-57-AM & 14,7 & $\begin{array}{c}\text { 1AS-133- } \\
\text { AM }\end{array}$ & ausente \\
\hline $1 \mathrm{AS}-31-\mathrm{AM}^{*}$ & ausente & 1AS-87-AM & ausente & $\begin{array}{c}\text { 1AS-136- } \\
\text { AM }\end{array}$ & ausente \\
\hline 1 AS-32-AM* & $\begin{array}{c}\text { Rel.vol. 8, } \\
\text { pg.155 } \\
\text { (ilegível) }\end{array}$ & 1AS-89-AM & ausente & $\begin{array}{c}\text { 1AS-137- } \\
\text { AM }\end{array}$ & ausente \\
\hline 1AS-33-AM* & ausente & $\begin{array}{c}\text { 1AS-105- } \\
\text { AM }^{*}\end{array}$ & 131,1 & $\begin{array}{c}\text { 1AS-139- } \\
\text { AM }\end{array}$ & ausente \\
\hline 1 AS-34-AM* & ausente & $\begin{array}{c}\text { 1AS-106- } \\
\text { AM }\end{array}$ & ausente & $\begin{array}{c}\text { 1AS-142- } \\
\text { AM } \\
\end{array}$ & ausente \\
\hline
\end{tabular}




\begin{tabular}{|c|c|c|}
\hline \multicolumn{3}{|c|}{ (B) Estudos Palinoestratigráticos Posteriores } \\
\hline Autor & Furo & $\begin{array}{c}1^{12} \text { Aparecimento } \\
\text { Grimsdalea }\end{array}$ \\
\hline Hoorn (1993) & 1AS-AA-AM & $89,00 \mathrm{~m}$ \\
\hline \multirow{3}{*}{ Silva (2004, 2010) } & $1 \mathrm{AS}-19-\mathrm{AM}$ & $218 \mathrm{~m}$ \\
\cline { 2 - 3 } & $1 \mathrm{AS}-27-\mathrm{AM}$ & $400,50 \mathrm{~m}$ \\
\cline { 2 - 3 } & $1 \mathrm{AS}-32-\mathrm{AM}$ & $132,00 \mathrm{~m}$ \\
\hline \multirow{2}{*}{ Leite (2006) } & $1 \mathrm{AS}-33-\mathrm{AM}$ & $239,90 \mathrm{~m}$ \\
\cline { 2 - 3 } & $1 \mathrm{AS}-37-\mathrm{AM}$ & $196,50 \mathrm{~m}$ \\
\hline D'Apolyto (2016) & $1 \mathrm{AS}-105-\mathrm{AM}$ & $326,20 \mathrm{~m}$ \\
\hline \multirow{2}{*}{ Kachniasz (2016) } & $1 \mathrm{AS}-31-\mathrm{AM}$ & $279,00 \mathrm{~m}$ \\
\cline { 2 - 3 } & $1 \mathrm{AS}-34-\mathrm{AM}$ & $199,95 \mathrm{~m}$ \\
\hline
\end{tabular}

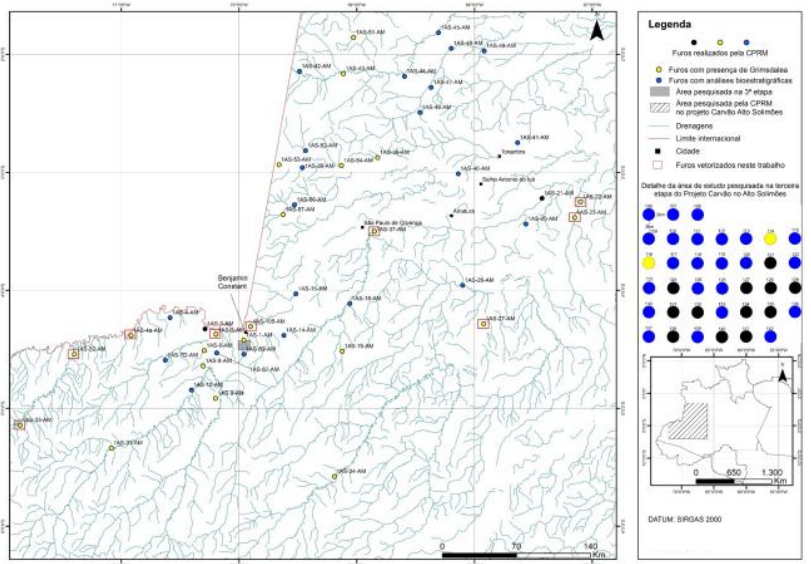

Figura 2 - Mapa dos poços e área do Projeto Carvão no Alto Solimões georreferenciados. Destaque em amarelo: poços com a presença do marcador bioestratigráfico. Destaque em vermelho: todos os poços vetorizados.

\section{Discussoões}

COMPARAÇÃO DOS PERFIS DE GEOFÍSICA COM PALEOAMBIENTES DESCRITOS NA LITERATURA Leite (2006) 32 amostras retiradas do furo 1AS-33-AM, especificamente da Formação Solimões, caracterizando grupos de palinomorfos associados aos ambientes: pântanos $\left(S_{1}, S_{2}\right.$ e $\left.S_{3}\right)$, planícies aluvionares $\left(A P_{1}\right.$ e $\left.A P_{2}\right)$ e lagos $\left(L_{1}\right.$ e $\left.L_{2}\right)$. Eles são sumarizados na Figura 5.a.

Os ambientes pantanosos encontram-se associados a respostas geofísicas mais lineares sem tendências, com valores maiores de RG e SP. Sendo assim, porção inferior da Formação Solimões caracterizada neste trabalho como de baixa energia pode ser definida como predominantemente pantanosa.

Poucas amostragens foram realizadas onde as linhas geofísicas apresentaram formas irregulares, caracterizadas aqui como de ambiente de alta energia, pois Leite (2006) faz a amostragens somente em material rochoso mais escuro, argiloso, visando aumentar sua probabilidade de encontrar palinomorfos. Contudo, é possível afirmar que as planícies aluvionares estão ligadas às linhas geofísicas com padrões mais irregulares. Leite (2006) indica uma alternância entre os ambientes lacustres/pantanosos e de planícies aluivais, também observado neste trabalho através dos padrões de alta e baixa energia intercalados no topo da Formação Solimões.

Hoorn (1993) realiza estudos palinológicos no testemunho 1AS-4a-AM, e com base na abundância de espécies a autora define os paleambientes da Formação Solimões. A Figura 5.b integra os estudos da autora com as imagens vetorizadas neste trabalho
As linhas geofísicas desta formação próximas à base e próximas ao topo, definidas aqui como de ambiente de baixa energia, são relacionáveis aos ambientes definidos pela autora como de Planície costeira. Contudo a porção central, aqui caracterizada como irregular (tendendo a quedas nos valores de potencial), oscila entre ambientes costeiros a aluvionares.

Sendo assim, podemos associar as linhas mais irregulares com mudanças bruscas (quedas nos valores de condutividade e respostas espelhadas nos valores de resistividade) a ambientes de planícies costeiras neste furo.

É importante ressaltar que assim como em Leite (2006) as amostragens neste furo foram em sua maioria realizadas em frações mais argilosas.

Quanto ao furo 1AS-105-AM, D'Apolito (2016) realiza estudos geológicos e palinológicos que permitem o autor fazer a interpretação de ambientes e análises das sequências estratigráficas de rochas amostradas da Formação Solimões. A Figura 5.c é a integração dos estudos do autor com as imagens vetorizadas neste trabalho.

Como dito anteriormente as linhas geofísicas indicam gradações, de ambientes de alta a baixa energia.

D’Apolito (2016) caracteriza 3 incursões marinhas, cuja a retrogradação é observada nas linhas em forma de sino do potencial espontâneo. Nota-se que as incursões marinhas, e a máxima inundação definida pelo autor estão ligadas aos valores mais altos de SP deste furo e de forma espelhada aos mais baixos valores de resistividade. Os sistemas fluviais, deltaicos estão associados a valores menores de SP e RG, com as linhas em decréscimo.

\section{AMBIENTE ANTES E APÓS O FAD DE GRIMSDALEA} MAGNACLAVATA

Hoorn (1993) e Hoorn et al. (2010) definiram a paleogeografia da amazônia durante a transição de paisagens "Cratônicas" a "Andinas". Os autores afirmam o surgimento de uma área alagada no oeste Amazônico, consequente do soerguimento das porções central e norte dos Andes ( $\sim 2 \mathrm{Ma})$, deslocando-se sentido leste da Amazônia e que de 10 a $7 \mathrm{Ma}$ evolui para uma extensa área alagada que desagua no Oceano Atlântico em um delta. O FAD de Grismsdalea se dá justamente neste período de alagamento, deslocamento e inversão no sentido do escoamento das águas para leste.

$\mathrm{Na}$ Figura 4 o que se observa após o surgimento deste grão na Formação Solimões para os furos 33 e $4 a$ é a deposição de um pacote sedimentar com 50-60m típico de ambientes de baixa energia (pantanosos e de planície costeira), diferentemente do que ocorre no furo 105 que passa de ambientes de alta a baixa energia, possivelmente retrogradacionais. Como este é o mais distante pode ser o representante das bordas dessas grandes áreas alagadas no sentido leste. Por ser praticamente todo composto por sedimentos meso a neomiocênicos, corrobora a hipótese de avanço de grandes lagos para leste, atual sentido do rio Amazonas . 0 furo $4 a$, apresenta nos últimos 10 metros de sedimentos da formação Solimões, uma mudança brusca nos padrões geoelétricos e de Raio Gama, que podem caracterizar ambientes similares aos últimos 180m desta 
formação no furo 33, contudo os registros que corroboram essa ideia podem ter sido erodidos no furo $4 a$.

\section{Conclusões}

Este estudo permitiu integrar dados até então não utilizados de perfilagem geofísica dos testemunhos perfurados na região Amazônia. Além disso, os dados geofísicos e palinológicos permitiram integrar resultados em busca de respostas sobre a evolução do Neógeno da Amazônia. Outros resultados desse trabalho foram: Criação do Banco de dados: as perfilagens geofísicas obtidas pelo Projeto Carvão no Alto Solimões são uma fonte de dados de grande importância até então não explorados, que poderão contribuir para a reconstrução paleoambiental do neógeno na porção oeste do Amazonas. Sendo assim os nove furos tabelados e vetorizados pelos autores deste trabalho, bem como as shapes da área e localização dos 84 furos do projeto, estarão disponíveis para que futuros trabalhos acadêmicos na região possam contar com uma base de dados atualizada.

Padrões geofísicos-geológicos para os ambientes deposicionais: as análises qualitativas dos padrões geofísicos quando confrontadas à literatura corroboram as hipóteses aventadas sobre os ambientes deposicionais, o que permite concluir que as perfilagens destes furos são uma fonte de dados confiável em estudos paleoambientais e que deve ser explorada.

\section{Agradecimentos}

Agradecimentos à Lógica Consultoria Sams por nos disponibilizar o software Strater 4.0 e ao Laboratório de Paleontologia e Palinologia da UFMT (PALMA).

\section{Referências}

D'apolito, C. 2016. Landscape Evolution In Western Amazonia: Palynostratigraphy, Palaeoenvironments And Diversity Of The Miocene Solimões Formation, Brazil. Tese de Doutoramento - Universidade de Birmingham, Birmingham.

Hoorn, C. 1993. Miocene incursions and the influence of Andean tectonics on the Miocene depositional history of northwestern Amazonia: results of a palynostratigraphic study. Palaeogeography, Palaeoclimatology, Palaeoecology, 105:267-309.

Jaramillo, C.; Rueda, M. \& Torres, V. 2011. A palynological zonation for the Cenozoic of the Llanos and Llanos Foothills of Colombia. Palynology, 35:46-84.

Kachiniasz, K. E. 2016. Análise Bioestratigráfica e Inferências, Paleoambientais da Formação Solimões (NW do Amazonas) com base em Palinomorfos.Trabalho de conclusão de curso - Universidade Federal de Mato Grosso, Cuiabá.

Leite, F. P. R. 2006. Palinologia da Formação Solimões, Neógeno da Bacia do Solimões, Estado do Amazonas: Implicações paleoambientais e bioestratigráficas. Tese de
Doutoramento - Instituto de Geociências, Universidade de Brasília, Brasília.

Maia, R.G.; Godoi, H.K.; Yamaguti, H.S.; Moura, P.A.; Costa, F.S.; Holanda, M.A.; Costa, J. 1977. Projeto Carvão no Alto Solimões. Relatório Final. CPRM-DNPM, $11 \mathrm{v}$.

Paz, J. D. S.; Ramos M. I. F.; Silva-Caminha S. A. F.; Moraes-Santos H. M. 2015. Depósitos flúvio-lacustres da Formação Solimões, Bacia do Solimões, Eirunepé (AM), Brasil. Contribuições à Geologia da Amazônia, 9: 81-92.

Silva, A. F. 2004. Palinologia do Neógeno da Amazônia Sul Ocidental, Brasil. MS Dissertation, Instituto Nacional de Pesquisa da Amazônia - INPA, Manaus.

Silva-Caminha, S.A.F., Jaramillo C.A., Absy, M.L., 2010. Neogene palynology of the Solimões Basin, Brazilian Amazonia. Palaeontographica, B 284, 13 e 79.

Zalán, P. V. 2004. Evolução fanerozóica das bacias sedimentares brasileiras. In: MANTESSO-NETO et al. (ed.) Geologia do Continente Sul-Americano. Rio de Janeiro, Beca, 595-614. 


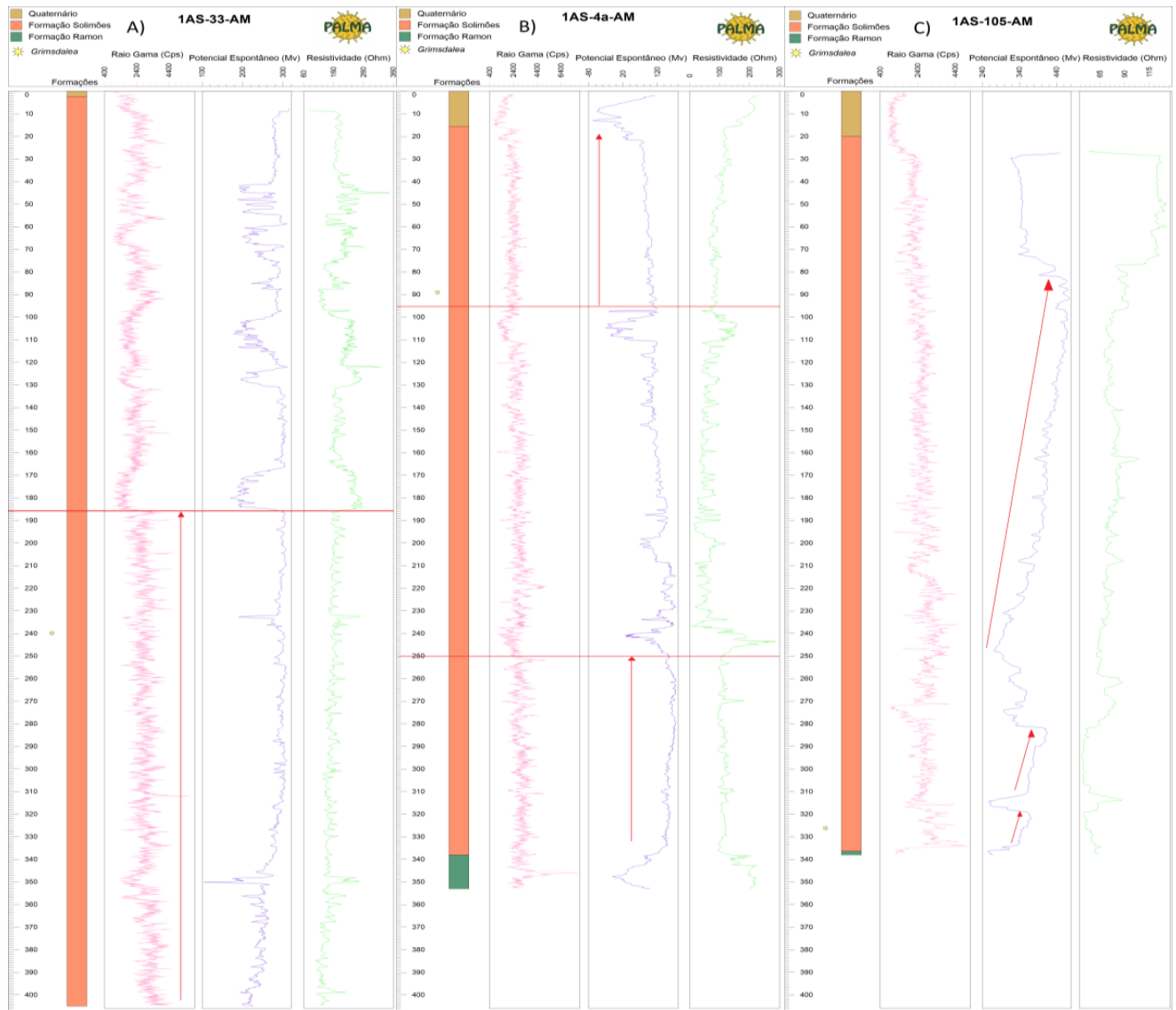

Figura $3-A) B)$ C) comportamento das linhas geofísicas demonstrados em vermelho indicam ambientes de alta e baixa energia e transicionais.

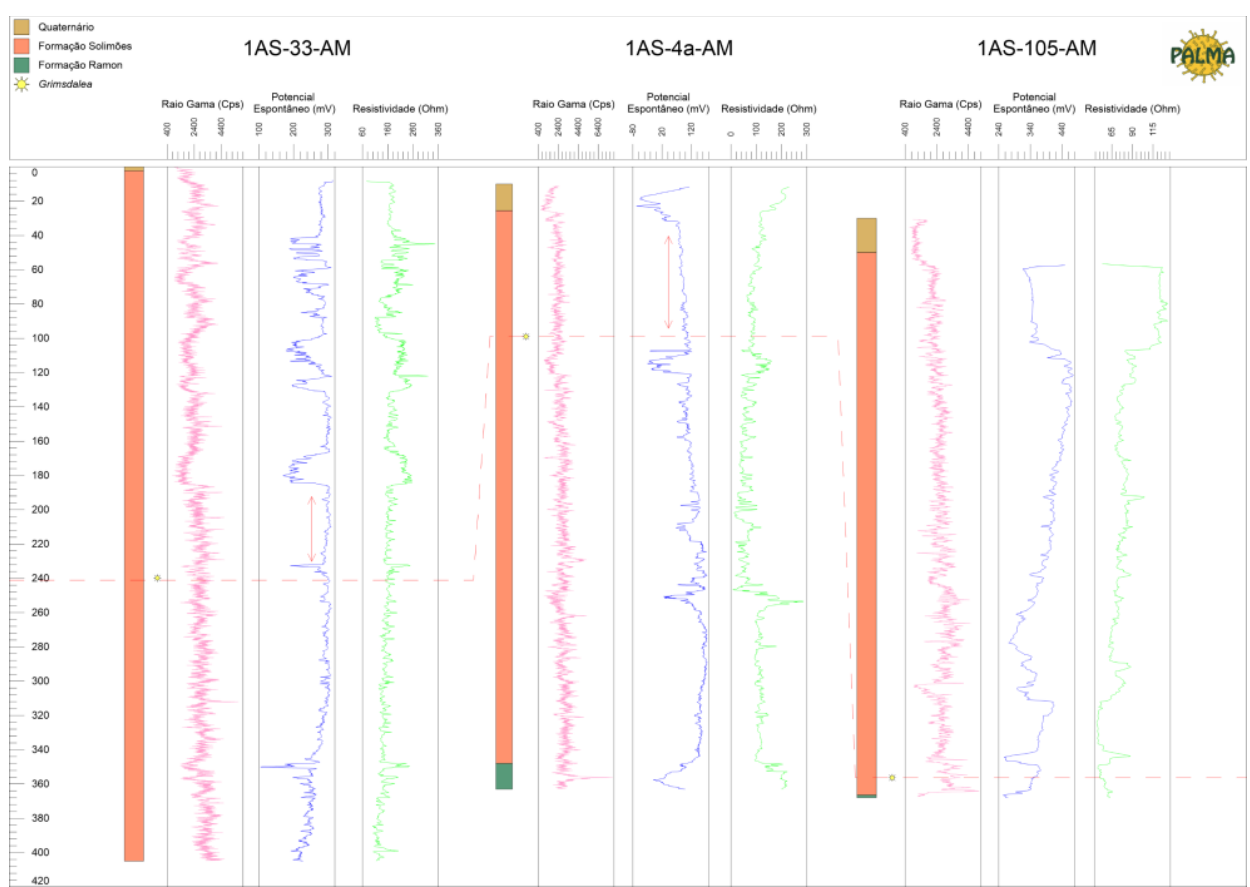

Figura 4 - Destaque em pontilhado mostra que após o surgimento do datum, na Formação Solimões, para os furos 33 e 4a ocorre deposição de um pacote sedimentar com 50-60 metros típico de ambientes de baixa energia (pantanosos e de planície costeira), diferentemente do que ocorre no furo 105 de ambientes de alta a baixa energia, possivelmente retrogradacionais, corroborando a hipótese de avanço de grandes áreas alagadas, no sentido leste durante o neógeno. 


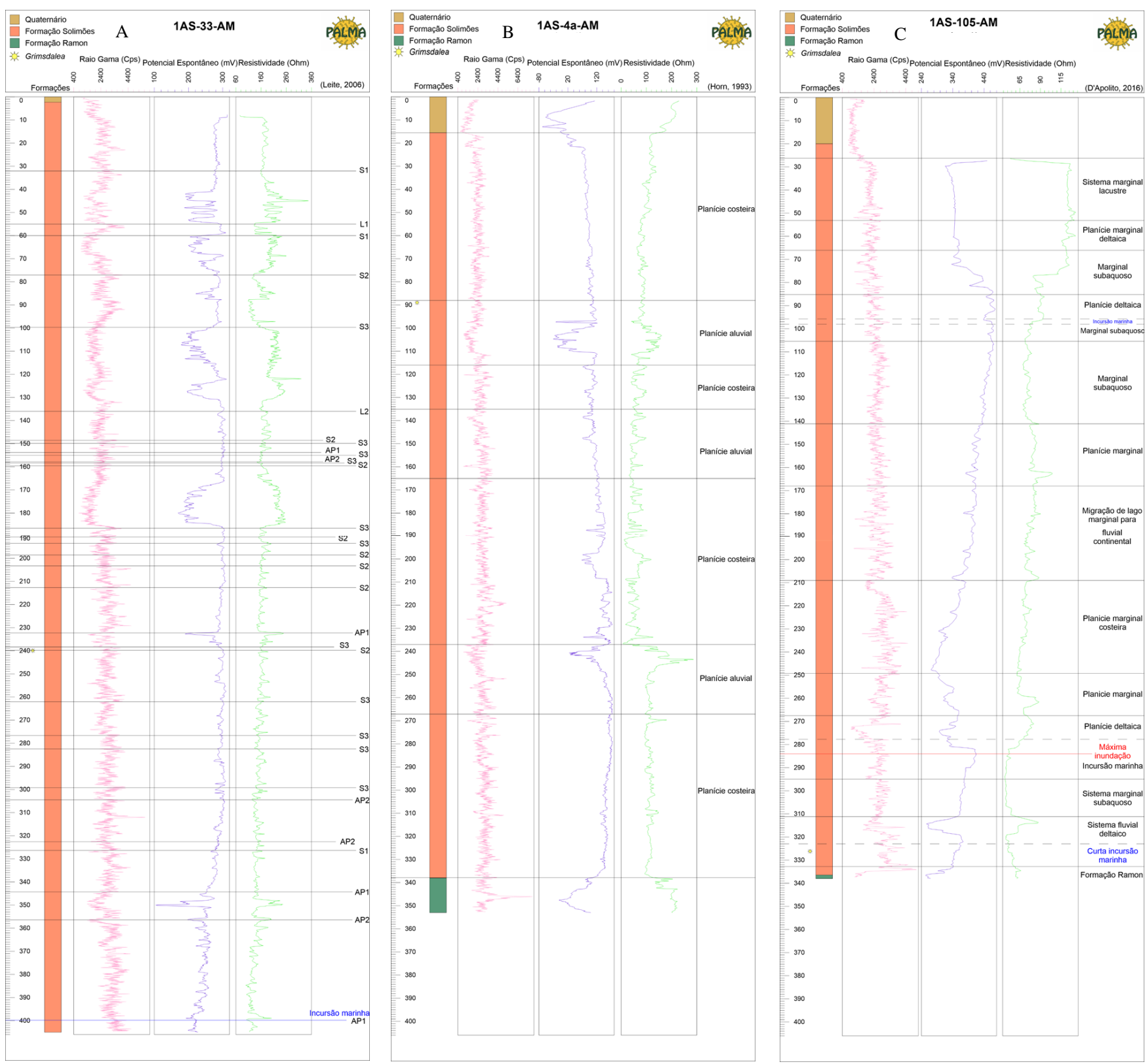

Figura 5 - A) B) C)Linhas geofísicas comparadas aos ambientes descritos na literatura, em destaque os trabalhos de Leite (2006), Hoorn (1993) e D’Apolyto (2016). 